\title{
Impacts of Covid-19 Pandemic on Purchasing Behaviour of Young Students
}

\author{
Le Thai PHONG ${ }^{1}$, Le Thi Thanh HA ${ }^{2}$, Nguyen Thi HANH ${ }^{3, *}$ \\ ${ }^{1,3}$ Faculty of Business Administration, Foreign Trade University, Hanoi, Vietnam \\ ${ }^{2}$ Program of Advance Business Administration, Foreign Trade University, Hanoi, Vietnam \\ *Corresponding author: hanhnt@ftu.edu.vn
}

\begin{abstract}
This paper aims to analyze young people's consumption perception as well as the influences of COVID-19 pandemic on young people's responsible behavior towards purchasing food. The research design involves a study on a sample of 119 students from Hanoi universities together with a development and validation of a regression model. Our results show that the effect of the COVID-19 from social influence variable is the most significant factor in the model, followed by risk perception and risk attitude. We hope that this small research would help provide more insights to the umbrella of crisis-related topics.

Research purpose:

Research aims to analyze young people's perception of consumption as well as the influences of COVID-19 pandemic on young people's responsible behavior towards purchasing food.

Research motivation:

Occurrence of COVID-19 pandemic has been considered by many economists to be a Black Swan event and there hasn't been any study carried out by Vietnamese researchers about the impacts of COVID-19 pandemic on customer purchasing behavior yet.

Research design, approach and method:

The research design involves a study on a sample of 119 students from Hanoi universities together with a development and validation of a regression model.

Main findings:

Our results show that the effect of the COVID-19 from social influence variable is the most significant factor in the model, followed by risk perception and risk attitude.

Practical/managerial implications:

We hope that this small research would help provide more insights to the umbrella of crisis-related topics.
\end{abstract}

Keywords: Purchasing behavior; student; Covid-19 pandemic

\section{INTRODUCTION}

Appearing in the famous Black Swan book by financial expert Nassim Nicholas Taleb, the phrase Black Swan is used to describe events that happen randomly with extremely small unpredictable probability but leaving behind an extremely heavy impact. It is impossible to foresee a Black Swan event until it actually takes place. In the past, numerous Black Swan events have occurred, leaving behind series of catastrophic consequences. The 9/11 terrorist attack, the 2008 credit crisis, the Lehman Brothers' bankruptcy in 2008, the 2010 BP gulf oil spill and the 2011 Japanese earthquake and tsunami are good examples of this phenomenon. Studies about these events have been conducted by hundreds of researchers over the world in order to forecast and come up with preparation and defensive actions against the future Black Swan events' occurrence.

At this time, the occurrence of COVID-19 pandemic has been considered by many economists to be a Black
Swan event. In just a few months, the Covid-19 pandemic has brought 210 countries to a standstill. The financial markets became weak and the social situation of nations became unstable. Nobody would have thought that a single strain of influenza virus could spread so drastically and cause such devastating consequences to so many industries, from financial investment, trade in services, import and export, industrial production, and civil aviation, tourism, energy to transportation. Hundreds of studies have been carried out by the global research community to understand the severe impacts of COVID-19 pandemic over the world.

In Vietnam, there have been several significant works about COVID-19 pandemic published by Vietnamese researchers, namely Importation and Human-to-Human Transmission of a Novel Coronavirus in Vietnam (Phan et al., 2020), Outbreak investigation for COVID-19 in northern Vietnam (Hai Nguyen Thanh et al., 2020), Duration of viral detection in throat and rectum of a patient with COVID-19 (Le Van Tan et al., 2020), The 
COVID-19 risk perception: A survey on socioeconomics and media attention (Toan Luu Duc Huynh, 2020). However, there hasn't been any study carried out by Vietnamese researchers about impacts of COVID-19 pandemic on customer purchasing behavior yet. Meanwhile this kind of research is crucial for marketers and businesses so as to build an appropriate marketing strategy, thereby promoting new customers to buy products and services or keeping old customers during crisis.

\section{LITERATURE REVIEW AND HYPOTHESIS DEVELOPMENT}

\subsection{Purchasing behavior}

According to Sarangapani (2009), what a customer buys, where a customer buys, how a customer buys and how often a customer buys form a customer's purchasing behavior. Customer purchasing behaviour is the way in which individuals, groups and businesses choose, purchase, use and dispose of products/services, ideas or experiences in order to satisfy unique needs and wants (Cant, 2010; De Mooij, 2010). According to Hoyer and Macinnis (2010), customer purchasing behavior demonstrates the totality of customer decisions regarding the purchasing, usage and disposition of products/services.

In 2004, Bourlakis and Weightman state that customer purchasing behavior is defined as the study of all of the activities required to obtain, purchase and dispose of products/services, including the decision-making process required besides these activities. Hoyer and Macinnis (2010) also state that customer purchasing behavior involves more than the process of purchasing tangible products. Customer purchasing behavior involves customer's decisions regarding the use of services, experiences, actions and ideas. Kengthon (2011) points out that customer purchasing behavior involves the manner in which a customer makes decisions on how to spend resources such as money, time and effort on products/services.

According to Kar (2010), the customer behavior is a combination of customer's buying awareness combined with external motivators to result in a change in the consumer's behavior. Usually the purchasing behavior takes many forms of customer's choices that can vary depending on a broad set of factors such as, earning, demographics, social and cultural factors (Kar, 2010 and Drakopoulos, 2008). Although there are many definitions of customer purchasing behavior, customer purchasing behavior can be described as all of the activities undertaken by a customer to make the final purchasing decision.

In 2002, Arnould pointed out that there are four groups of customers purchasing behavior: programmed behavior; limited decision-making purchasing behavior; extensive decision-making purchasing behavior and impulsive buying. Programmed behavior (also called habitual behavior) is distinguished by low complexity and little information search. This process is usually known as routine purchase of low-cost items that customer is used to buy out of habit such as coffee, newspapers, bus tickets, etc. Limited decision-making buying behavior involves reasonable level of decision making and relatively low amount of information search in order to generate a purchase. The extensive decision-making buying behavior is identified as being the opposing type to the limited decision-making buying behavior (Foxall and Goldsmith, 1994). Customers would spend a relatively longer share of time on information search and would take longer period to decide regarding this purchase. This process is usually adopted when purchasing infrequent expensive product that takes a large share of the customers' income and involves higher psychological risk (Peter and Olson, 2007). Finally, the impulsive buying is a decision made unconsciously and induced by an external stimulus that would make a specific product appear attractive and irresistible to the customers (Wells and Prensky, 1997).

In conclusion, knowledge about customer purchasing behavior could be a great source of competitive advantage as it will result in marketer formulating better marketing strategies based on rigorous theories rather than on opinions and on hunches (Hawkins and Mothersbaugh, 2010). The study of customer behavior has been so long attracting many researches because of its imperative importance to businesses around the world. By predicting customer behavior, a business can understand customers' needs, and can work on fulfilling the needs and meeting the expectations of their customers (Nistorescu and Puiu, 2009). This would eventually help businesses to maintain their prosperity and attain their long-term goals.

\subsection{Purchasing behaviors during a health crisis}

It was believed that one of the first relevant studies was made by Kelly and Schewe (1974) about the reaction of American consumers towards stagflation from 1973 to 1974. Their article emphasizes the measurement of customers' expectations to understand customers purchasing behavior in the crisis, regarding spending vs. savings, postponing discretionary expenditures, awareness of credit usage, and possible shifts (temporarily or permanently) in life style patterns.

In 1980, Shama also scrutinized this crisis's impacts on customers in New York and concluded the fact that the recession created changes in customers' motivations, values, attitudes and expectations. He noticed main changes in consumers' behavior were the desire to buy less, the postponing of long-lasting product purchase, the focus on comparing the products and an extension of purchase duration, the change of purchase habits and waste riddance.

Friszbein et al. (2003) pointed out that the harsh economic crisis period from 2001 to 2002 in Argentina generated three groups of households, each of which adopted three different types of strategies against the 
crisis. The first group applied adaptive strategies. The second group used active strategies such as producing home goods to sell, a new member of the family entering labor market, at least one member of the family started to work longer hours, at least one member of the family emigrated permanently in another city, another province to earn money, etc. The third group utilised strategies called social network, which means searching for living support provided by people outside the household.

In 2002, Robles et al. conducted a research on the same crisis and identified the following changes in Argentinean customer behavior: avoiding long-term financial commitments by omitting major purchases (cars, houses, holidays, etc.,) re-evaluating consumption mix by increasing expenses for basic products, changing purchase habits by guiding the consumers toward self-service, discount outlets and hypermarkets, searching for a favorable quality-price balance. Zurawicki and Braidon (2005) also discovered the same main patterns in consumers' behavior change in a research identifying middle-class Argentinean consumers' reaction in the same crisis.

Ang et al. (2000) pointed out that customer purchasing behavior was affected in many ways due to Asian crisis. To be particular, customers searched for extra information, consumed less all product categories and get rid of waste, bought more domestic products rather than foreign products, chose discount and neighborhood shops, and substituted products, compared to normal time. The downturn required customers to revise their purchasing behaviors and budget distribution.

Urbonavicius and Pikturnien (2009) stressed that recession made customers' behavior more emotional, and identified six types of reactions: 1) continuing with the same behavior without any change; 2) reducing spending to survive; 3 ) reducing spending to make some savings; 4) concentrating on short-term increase of living quality, as long as it can be afforded; 5) improving living quality by consuming more; 6) improving living quality by consuming better quality products and services.

Many other researchers also indicated that crises made customers react more emotionally than rationally. Two Romanian researchers (2011) analyzed several studies made in various crises: economic crisis (Kelley and Schewe, 1975; Shama, 1978, 1980; Shipchandler, 1982; Ang et al., 2000; Ang, 2001; Zurawicki and Braidot, 2005; Dutt and Padmanabhan, 2009; Garling et al., 2009; Fiszbein et al., 2003; Qelch and Jocz, 2009; Robles et al., 2002; Kittiprapas, 2002; Stegaroiu and Stegaroiu, 2010; Urbonavicius and Pikturnien, 2010), food security crisis (Miller and Reilly, 1994; Pennings et al., 2002; Jin and Koo, 2003; Lusk and Coble, 2005; Kalogeras et al., 2008; Wansink, 2004), terrorism crisis (USA, 2001), public health security crisis (Saad, 2009). The results of the analysis made an indication that no crisis is similar to another, considering causes, evolution, outcomes, severances, etc. Interestingly, the psychological factors play an important role in shaping customer purchasing behavior in crises.

When a crisis happens, risk occurs in various forms: unemployment, inflation rise, freezing or decrease of salaries, decrease of purchasing power, and decrease of deposits, etc. There is consensus that risk is associated with uncertainty and generates consequences. Crisis is labeled as uncertain and risk-generating situation (economic shocks) with significant effects on consumers. The two aforementioned Romanian researchers developed a model of how customer behavior is affected in uncertain and risk-generating situation. In the model, the two Romanian researchers pointed out that the change of customers' behavior is determined by risk perception and risk-generating situation aversion. The Romanian researchers then developed a customers' behavior model in two psychological dimensions considering the manner in which they interact to obtain a better picture of the intensity and change directions at the level of behavior in crisis.

\subsection{Impacts of risk perception and risk attitude on consumer purchasing behaviors}

According to the group of Romanian researchers, risk perception is the interpretation that an individual makes with a view to the chances to be exposed to risk content and to the estimated capacity to control the exposure. This personal interpretation generates emotions such as panic, anxiety, stress, fury, etc. On the other hand, each individual like or dislikes the risk-generating situations in a certain measure, reflecting each person's risk-attitude that leads to certain feelings such as panic, confidence/ lack of confidence in brands, companies, government, media, future. Risk attitude is a hypothetical construction reflecting whether the individual likes or dislikes risk-generating situation and risk aversion.

P. Amalia and P. Ionut (2009) pointed out that the most important factors which determined the customers' behavior in risk-generating situations are: risk attitude and risk perception. Risk attitude reflects consumer's interpretation concerning to the risk content and how much he or she dislikes the content of that risk. Risk perception reflects the interpretation of the consumer of the chance of being exposed to the risk content.

Moreover, in the study of customer behavior to the BSE (Mad Cow Disease) crisis, Pennings (2004) selected risk attitude and risk perception as the two fundamental drivers of decision behavior under uncertainty. According to the researcher, risk attitude deals with the consumer's interpretation of the risk content and how much (s)he dislikes that risk content; whereas, risk perception deals with the consumer's interpretation of the chances of becoming exposed to the content of the risk (Pennings and Smidts, 2000). Risk attitude reflects a consumer's general tendency to a particular risk in a consistent way, and hence is formed by the content of 
that risk. Risk perception reflects the consumer's own interpretation of the likelihood of becoming exposed to the content of the risk and may therefore be defined as a consumer's assessment of the uncertainty of the risk content inherent in a particular situation (Pennings, Wansink and Meulenberg 2002). Hence, it is driven by the likelihood of exposure to the risk content.

Risk attitudes range from extremely risk aversion (i.e., refusing any risk under any condition) to extremely risk seeking (i.e., always preferring a risk-carrying outcome), while risk perceptions range from high to none at all. It is the interaction between both concepts that drives decision behavior, as it reflects consumers' tendency to deal with the risks inherent in the risk content and the risks that their reactions to this risk content generate. Yet, whether or not they will actually take precautions depends on their risk perception: if these consumers estimate the likelihood of crisis at zero, they will not take any precautions. Only when the consumers are both risk-averse and perceive risk at the same time, will they show preventive behavior (towards food contamination) As the results, two hypotheses are generated:

H1: Customers' risk perception will have a positive influence on their purchasing behavior.

H2: Customers' risk attitude will have a positive influence on their purchasing behavior.

\subsection{Impacts of social influence on consumer purchasing behaviors}

According to Gayithri (2020), fear of scarcity creates a sense of urgency, which leads individuals to mitigate their risk by acting collectively as a part of a group and often making decisions as a group that they would not make as an individual. This type of behavior is known as herd behavior, the tendency of individuals to copy the actions of other participants. This psychological phenomenon that goes with the herding is a concept called the bandwagon effect which refers to things people do primarily because of other people are doing it, regardless of their own beliefs, which they may ignore or override. According to some research, as more people come to believe in something, others also "hop on the bandwagon" regardless of the underlying evidence. The tendency to follow the actions or beliefs of others would occur because individuals directly prefer to conform, or because individuals derive information from others. Both explanations have been used for evidence of conformity in psychological experiments. According to this concept, the increasing popularity of a product or phenomenon encourages more people to "get on the bandwagon". It can be inferred that herd behavior and bandwagon effect may have also played a role in customer behavior amid COVID- 19 .

In addition, we realized that lockdown orders from government, media influence and peer pressure in COVID-19 pandemic also determined customer purchasing behavior. Social influence (also known as external factors) are influences that do not occur from within the individual but from elsewhere like the environment and others around the individual. We understand that social influence would probably impact risk attitude and risk perception and then risk perception and risk attitude would control customer purchasing behavior. However, during the course of COVID-19 pandemic, from observed that the people around had no high-risk attitude or risk perception about COVID-19, yet were affected by bandwagon effect and the lockdown orders to change purchasing behavior. Besides, the fact that the government issued lockdown orders is a standout of COVID-19 pandemic, which makes everyone stay indoors and therefore their behavior is forced to change despite their risk perception and risk attitude.

H3: Social influence will have a positive influence on their purchasing behavior.

Our research analyses the impact of COVID-19 pandemic on the young people's purchasing behaviour. We propose a conceptual model based on the Theory of Planned Behavior (TPB) (Ajzen, 1991), one of the most frequently used constructs in studies purchasing intention of various sectors.

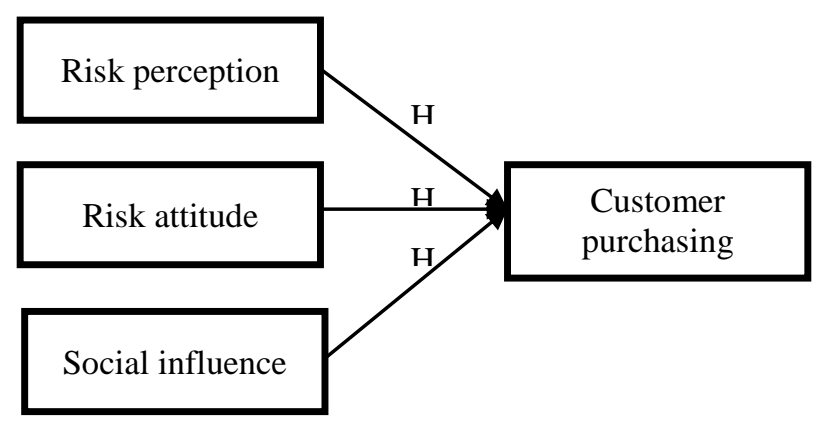

Fig 1. The proposed research model

\section{METHODOLOGY}

\subsection{Sample}

The questionnaire is set up to collect for recommended research. As the first version of the questionnaire is created, it was sent out to 10 people to test whether the questionnaire is clear enough. After that, adjustments were made to improve the questionnaire. The online survey is carried out in the form of Google Forms since it is the fastest and most convenient way and it also can reach a wide variety of audience. We send the link of the questionnaire on Facebook and asks friends and acquaintances to complete the survey as well as share it to their own network of friends and acquaintances so that the survey can be reached by more people. There are 136 people submitted answers for the survey. Of those 136, 119 responses met requirements for further survey analysis. According to Hair and ctg (2006), the minimum sample size to use EFA is 50, preferably 100 and the number of observations / measurement variables is 5: 1, 1 measurement variable needs a minimum of 5 observations. The sample selection formula is: $\mathrm{N}=5 *$ 
items. Therefore, the sample size would be $5 * 23=115$.

\subsection{Measurement}

For the measurement scale, the most widely used in quantitative research is the 5-point Likert scale. It usually includes an odd number of options, ranging from 1 (strongly disagree) to 5 (strongly agree) to evaluate the answers of respondents and then to test the validity of the hypotheses. The option in the middle of the scale is the neutral one. According to the recommended research model and the suggested hypotheses, the study needs to evaluate 3 factors that affecting purchasing behavior of young customers in Hanoi: (1) risk attitude, (2) risk perception, (3) social influence and the dependent variable customer purchasing behavior.

To measure the variables, we identified in the literature reliable items and we adapted the items to our research purpose. The variables and the items were adapted from the literature as following:

RP: Risk perception was adapted from Amalia \& Ionut (2009); Pennings (2004)

RA: Risk attitude was adapted from Amalia \& Ionut (2009); Pennings (2004)

SI: Social influence is developed from social influence theory of Friedkin (1998).

PB: Purchasing behavior was adapted from Ajzen (1991)

To test our model, we used a linear regression analysis by using SPSS software. To find out if gender makes a difference in customer purchasing behavior we used T-Test analysis. In Table 1, we evaluated the reliability values (cronbach's alpha) which, according to Hair et al. (2017), must be greater than 0.6.

Table 1: Construct reliability

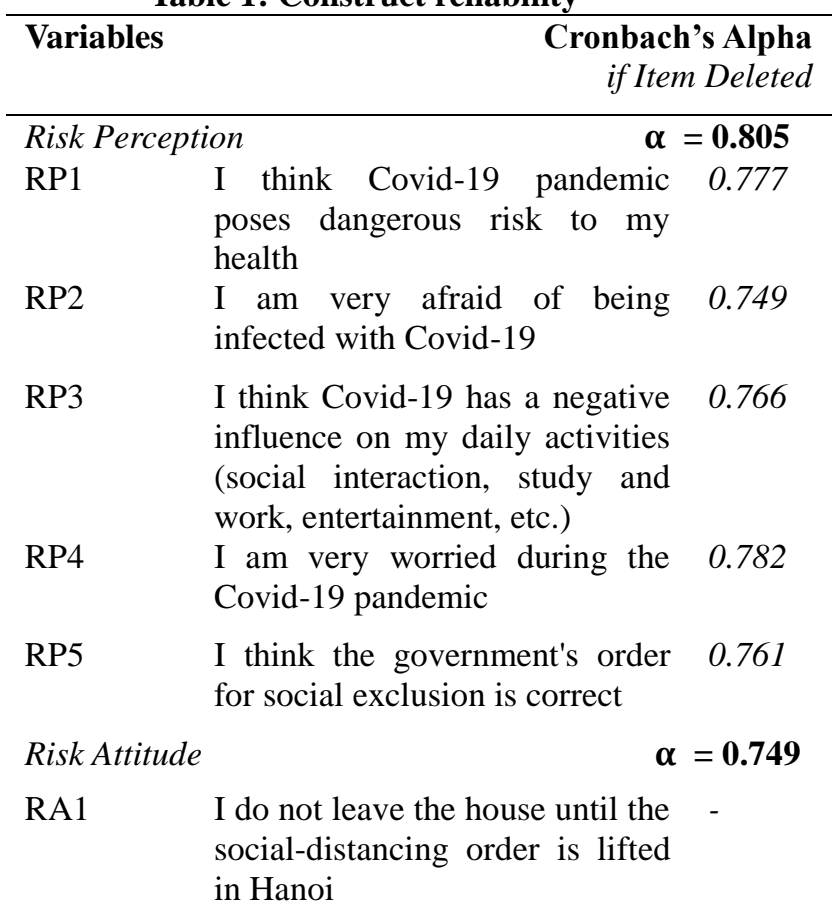

RA2 I continue to wear a mask when

0.747 going to public after the social-distancing order is lifted in Hanoi

RA3 I choose to shop online so I

0.713 don't have to leave home during the Covid-19 pandemic

RA4 I think that stockpiling groceries is necessary in the Covid-19 epidemic

RA5 I think that stockpiling drugs and healthcare products is necessary in Covid-19

RA6 I am very concerned about news regarding Covid-19 during the pandemic occurrence

Social Influence

$\alpha=0.730$

SI1 I have stockpiled groceries 0.556 because everybody is doing it

SI2 I have hoarded many health 0.648 protective gear because everyone is doing it

SI3 I only stayed at home because of the government 's social distancing order.

SI4 I switched to online shopping during the COVID-19 because my friends did so

SI5 I felt Covid-19 is dangerous because the media reported a lot about it

Purchasing Behavior

$\alpha=0.782$

PB1 I switched to online shopping 0.809 due to Covid-19 pandemic

PB2 I have hoarded a lot of 0.638 necessities (food, personal hygiene items)

PB3 I have stockpiled many health-protection items (medicine, mask, hand sanitizer, etc.)

PB4 I have reduced my spending 0.742 compared to normal in the Covid-19 epidemic

PB5 I only bought the utmost 0.708 necessities in the Covid-19

PB6 I continue to buy my favorite branded goods in the Covid-19 pandemic

PB7 I focus on low cost when choosing to buy products during the COVID-19 pandemic, compared to normal time

Source: Authors' analysis

Analyzing the results depicted in Table 1, we notice that a series of items have a value of less than 0.6 and for the validation of the evaluation scale, we have eliminated 
them. Risk attitude, risk perception, social influence and customer purchasing behavior are evaluated using Cronbach's alpha. If Cronbach's alpha is greater than 0.6, the measurement scale is acceptable (Hair, 2018). As a result, RA1, RA6, SI3, PB3, PB6, PB7, which have Corrected Item - Total Correlation smaller than 0.3, are removed during the process so that Cronbach's Alpha achieves results larger than 0.6. After the removal, all the remaining variable meet Cronbach's Alpha requirements. Therefore, it can be said the measurement of researched variables has reached the necessary reliability and is suitable for the next analysis stage. As a result, EFA factor analysis is appropriate for this study.

After testing the reliability of the measurement scale, item RA4, RA5 are removed. KMO (Kaiser-Meyer-Olkin) must have value between 0.5 and 1, sig Bartlett's test must be less than 0.05, as results, $\mathrm{KMO}=0.752$, factor analysis is accepted with research data set. Sig Bartlett's Test $<0.05$, factor analysis is appropriate Eigenvalue must be no less than 1, total variance explained must be no less than $50 \%$, and factor loading must be more than 0.35 , as the sample size for this research is 119 (Loc, 2015). Eigenvalue $=1.169>1$ and three meaningful factors, which summarize the best information, are extracted. The total variance extracted $=62,254>50 \%$ which indicates that the EFA model is suitable. The 12 observed variables are grouped into 3 factors, all of which have a Factor Loading factor greater than 0.5 .

Table 2. Rotated component matrix

\begin{tabular}{llll} 
Variables & Component & & \\
& $\mathbf{1}$ & $\mathbf{2}$ & $\mathbf{3}$ \\
RP3 & 0.788 & & \\
RP5 & 0.736 & & \\
RP1 & 0.720 & & \\
RP2 & 0.702 & & \\
RP4 & 0.578 & & \\
SI1 & & 0.874 & \\
SI2 & & 0.713 & \\
SI4 & & 0.713 & 0.890 \\
SI5 & & 0.569 & 0.734 \\
RA2 & & & 0.576 \\
RA6 & & & \\
RA3 & & & \\
\hline
\end{tabular}

Table 2 present a rotating matrix that eliminates unimportant loading factors and shows the convergence factors. It is shown that all the attributes of each factor are loaded in the corresponding component. And the three components can explain the variance of all the variables from the total variance explained.
Result of Pearson correlation of independent variables $\mathrm{RP}, \mathrm{SI}, \mathrm{RA}$ with dependent variable $\mathrm{CB}$ is less than 0.05. Thus, there is a linear relationship between these independent variables and the dependent variable.

Table 3. Pearson correlation

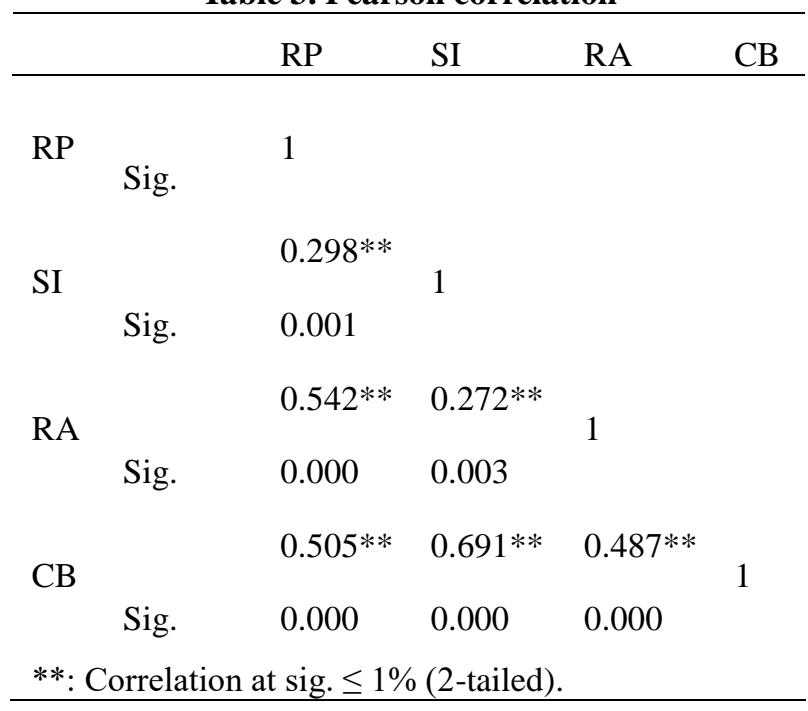

The Pearson correlation table 3 shows that all the independent variables are positive with the dependent variables, but all are moderately correlated, none are too closely correlated (Pearson value is close to 1) with the dependent variables. The strongest correlation of all is between SI and CB because $r$ coefficient is 0.691. Pairs of independent variables are quite correlated with one another at an acceptable level; no pairs of independent variables are completely compatible. As a result, it is likely that there will be multi-collinearity. The result is favorable for the regression analysis.

\section{RESULTS AND DISCUSSION}

\subsection{Results}

Next step, in order to measure the level of significance in hypothesis testing, is to analyze the significance of relationship between constructs (Table 4) using regression model. R-Square is equal to 0.597 showing that the independent variables included in the regression affect $59.7 \%$ of the change of the dependent variable, the remaining $40.3 \%$ is due to out-of-model variables and random errors. Durbin-Watson coefficient $=1,577$, which is in the range of 1.5 to 2.5 , so no first-order correlation occurs. Sig test $\mathrm{F}$ is equal to $0.00<0.05$, so the multiple linear regression model is suitable for the data set and can be used. Sig tests t coefficients of the independent variables are less than 0.05 , so these independent variables are meant to explain the dependent variable, no variables are excluded from the model. The VIF of the independent variables is less than 2 , so no linear multiplication occurs. Regression coefficients are greater than 0 . Thus, all the independent variables included in the regression analysis have a positive effect on the dependent variable. 
Table 4: Regression analysis

\begin{tabular}{lllll}
\hline & $\begin{array}{l}\text { Standardize } \\
\mathrm{d}\end{array}$ & \multicolumn{3}{c}{ Collinearity } \\
& $\beta$ & Sig. & $\begin{array}{l}\text { Toleranc } \\
\text { Model }\end{array}$ & VIF \\
\hline Constant & & 0.051 & & \\
RP & $0.221^{* *}$ & 0.002 & 0.681 & 1.468 \\
RA & $0.213^{* *}$ & 0.003 & 0.693 & 1.444 \\
SI & $0.567^{* * *}$ & 0.000 & 0.894 & 1.119 \\
\hline
\end{tabular}

Based on the magnitude of Beta standardized coefficients, the order of the strongest to weakest independent variables on the $\mathrm{PB}$ dependent variable is: SI (0.557)> RP (0.221)> RA (0.212), corresponding to:

Table 5. Hypothesis results

\begin{tabular}{llll} 
\# & Hypothesis & & Result \\
\hline H1 & $\begin{array}{l}\text { Customers' risk perception has a Supported } \\
\text { positive influence on their } \\
\text { purchasing behavior. }\end{array}$ & \\
H2 & $\begin{array}{l}\text { Customers' risk attitude has a Supported } \\
\text { positive influence on their } \\
\text { purchasing behavior. }\end{array}$ \\
H3 & $\begin{array}{l}\text { Social Influence has a positive Supported } \\
\text { influence on their purchasing } \\
\text { behavior. }\end{array}$
\end{tabular}

All of the unstandardized coefficients are bigger than 0 , all three independent variables have positive impacts on customer purchasing behavior. The effectiveness of each independent variable is shown in the standardized regression equation below:

$$
\mathrm{PB}=0.221 * \mathrm{RP}+0.213 * \mathrm{RA}+0.567 * \mathrm{SI}
$$

\subsection{Discussion}

\section{Hypothesis 1}

Is validated $(\beta=0.221, \mathrm{Sig} .=0.002)$. Theoretically, risk perception has an impact on customer purchasing behavior and research results have confirmed this theory. With Beta results being 0.221 for risk perception, this indicates that a significant portion of young customers in Hanoi would change purchasing behavior because of how they feel about the COVID-19 crisis (the level of risk aversion), and how they interpret the chances of being exposed to the crisis. This result means that in terms of risk perception, the more customers perceive their chance of being exposed to COVID-19, which would result in their negative emotions like fear, worry, depression, pessimism, the more purchasing behavior of customers would change.

\section{Hypothesis 2}

Is validated $(\beta=0.213$, Sig. $=0.003)$. Our research shown that risk attitude have an impact on customer purchasing behavior and research results have confirmed this theory. Therefore, if risk attitude increases 1 unit, customer purchasing behavior will increase 0.213 unit. This result means that the more customers dislike the crisis, which would lead to actions of risk aversion such as "do not leave the house", "continue to wear a mask when going to public after the social order is lifted", "stockpile" for not going out a lot, the more customers are likely to change their purchasing behavior.

In COVID-19 pandemic, according to Toan Luu Duc Huynh (2020), the overwhelming amount of information and the overuse of mass media in communicating the COVID-19 virus (risk perception) might contribute to overreaction, unwarranted fear, and an overly pessimistic feeling (risk attitude) in perceiving the current risk, which in turn would affect purchasing behavior of anyone including young customers in Hanoi.

\section{Hypothesis 3}

Is validated $(\beta=0.567, \mathrm{Sig} .=0.000)$. Social influence is the most impactful factor in the model. This result is very practically reasonable in COVID-19 pandemic. According to Gayithri Kuruppu (2020), herding and bandwagon effect had primarily contributed to the panic buying occurrence during the COVID-19 pandemic. The fact that health protective products become hot purchasing items which quickly go out of stock have proved that unknowingly following the crowd to mitigate risk without full understanding of risk content is prevalent in COVID-19 pandemic. Besides, according to reports by EY and McKinsey, lockdown orders from governments render every kind of customers stay at home and change their purchasing behavior correspondingly to suit their conditions both temporarily or permanently. The fact that Hanoi implemented social isolation for one month have affected young customer purchasing behavior. For example, eating out, in-store shopping and outdoor entertainment services were prohibited. Meanwhile, online shopping becomes a convenient "marketplace" substitute, delivery shipping becomes more popular. Moreover, with the effect of heuristics (a quick mental decision-making process) shown in Gayithri Kuruppu (2020)'s study, pressure from media and peer would make young customers change their purchasing behavior for reason of safety without much thinking.

\subsection{Managerials implications}

It can be seen that customer purchasing behavior is most affected by social influence in COVID-19 crisis. However, social influence cannot be controlled by anyone. With that said, regarding business owners, business owners do not need to pay too much attention to the social influence. Instead, business owners should focus on surviving the crisis, developing what is the companies' advantages and maintaining business aspects that are doing fine. Opening a new business in crisis to take advantage of the market lacking seriously 
specific products needs to be considered carefully. In this case, considering financial capacity is very important because a wrong move can cost a lot of money. In crisis, the company needs a lot of cash to survive.

During crisis, providing businesses that serve what customers is hoarding would be the most profitable. For example, in the COVID-19 pandemic, selling masks and hand sanitizers is the hottest business. However, business owners do not need to completely divert the company to another field to gain immediate profits. The lack of readiness and understanding of the new business areas would make it super risky to execute new business ideas in crisis. In terms of recommendations for marketers, first marketers should adjust their media content based on customers' moods and expectations customer psychology. During the outbreak, maintaining brand reputation with public interest should be a priority over sales promotions, product communications or efforts to increase awareness. Communication channels need to combine skillfully. If marketers work in FMCG, marketers should strengthen FMCG sales online channels. The health crises not only make people refer to shop online but also make older generations, who have a "technology refusal" mentality, begin to accept this type of shopping. During crisis, marketing how companies react to the crisis would effectively create a better brand image because positive actions of brands in the sensitive time would have a great impact on attitudes and emotions of customers.

We acknowledge that the research has many shortcomings. Firstly, the uncontrolled spread of COVID-19 pandemic causes events to occur one after another. One event is the cause of the other, and events affect or overlap one another successively like the dominoes in a complicated way. Therefore, it is extremely difficult to attribute the impacts of COVID-19 to certain variables that affect consumer behavior. Customer purchasing behavior will certainly be affected by more than one specific factor. For example, social distancing keeps people at home, business closes in mass, causing many people to lose their jobs or get wages cut. Financial instability during the crisis is also an impact of COVID-19 on customer purchasing behavior that the research has not covered. However, if the customer is well prepared financially and have working capacity, the occurrence of COVID-19 pandemic will not affect their purchasing behavior very much.

Not only does COVID-19 cause governments to order social distancing, harming many businesses, but it also forces governments to constantly print out money and reduce lending rates to save the economies. The rise in inflation and debt would affect customers' psychology when shopping. Customers would more likely to invest in gold, real estate, instead of buying consumer goods. Or customers would spend more on savings to have money in storage for the future. Also, modern technology is helping people maintain the normal life possible in COVID-19 pandemic. Customers not only shop more online to meet their essential needs, but also purchase new online technological services to serve learning and working from home.

The study hasn't shown how staying at home in a long time during COVID-19 pandemic has affected customers' purchasing behavior. Besides, the mental and psychological impacts caused by COVID-19 on customers have not been exploited deeply. Meanwhile, psychological factor is believed to be the most dominant factor influencing customer purchasing behavior in crisis. Although the surveyed respondents are appropriate for the survey, the sample is believed to be not diverse and objective enough to cover the population of young customers in Hanoi.

For future research suggestions, we may suggest future research to build upon findings of this research and address unanswered aspects of research problem. There are limitations of this research; therefore, we propose future research suggestions that address those limitations. Besides, we have addressed research problem within the subjects of young customers in Hanoi; therefore, constructing the same research in a new context, location and/or culture would help validate the value of this research. Reassessing and expanding theory, framework or model of this study is another way for future research. Future studies may address the effects of other "Black swan" events, emergence of a new theory or evidence and/or other recent phenomenon on this research problem.

\section{CONCLUSION}

COVID-19 pandemic is considered to be a once-in-a-hundred-years event. It is the rapid uncontrolled spread of COVID-19 pandemic that poses the greatest threat to the world. The damage caused by COVID-19 pandemic to the global economy is estimated to be trillions of dollars, followed by a series of short-term remedies such as printing money, reducing interest rates, which will definitely cause further damage to the future economy. COVID-19 pandemic causes changes to not only many nations' finances, economies, societies, but also consumer behavior. Inspired by the phenomenon of COVID-19 pandemic and the marketing lessons on customer purchasing behavior. Impacts of COVID-19 pandemic is extremely complicated because they are a chain of events overlapping each other. However, we have succeeded in attributing impacts of COVID-19 pandemic to three factors called risk attitude, risk perception, and social influence, which directly affect customer purchasing behavior, to develop a reasonable research model. The research relies on multi-regression analysis, finding out that the social influence has the strongest impact on customer purchasing behavior. Despite limitations of the research, we hope that this small research would help contribute a small insight to the umbrella of crisis-related topics. 


\section{ACKNOWLEDGMENTS}

The authors gratefully acknowledge the contribution of reviewers and ICECH2021 organizers.

\section{REFERENCES}

[1] Amalia, P., (2011), "The change of consumers' behavior in crisis conditions: A psychological approach to the empirical evidence from Romania", African Journal of Business Management, 5(28).

[2] Amalia, P. and Ionut, P., (2020), "Consumers' Reaction And Organizational Response In Crisis Context", [online] Citeseerx.ist.psu.edu. Available at:

$<$ http://citeseerx.ist.psu.edu/viewdoc/download?do $\mathrm{i}=10.1 .1 .890 .252 \& \mathrm{rep}=\mathrm{rep} 1 \&$ type $=\mathrm{pdf}>$ [Accessed 5 June 2020].

[3] Ang, S., Leong, S. and Kotler, P., (2000), "The Asian Apocalypse: Crisis Marketing for Consumers and Businesses", Long Range Planning, 33(1), pp.97-119.

[4] Committee for the Coordination of Statistical Activities, (2020), "How COVID-19 Is Changing The World: A Statistical Perspective", [ebook] UNCTAD. Available at: $<$ https://unstats.un.org/unsd/ccsa/documents/covid1 9-report-ccsa.pdf $>$ [Accessed 28 June 2020].

[5] Fisher, A., (2020), "More Than 90 Countries Request IMF Bailout. [online] Aljazeera.com. Available at: <https://www.aljazeera.com/news/2020/05/90-count ries-request-imf-bailout-200523125117126.html> [Accessed 8 June 2020].

[6] Friedkin, N. E. (1998). A structural theory of social influence. Cambridge University Press.

[7] Fiszbein, A., Giovagnoli, P. and Aduriz, I., (2003), "The Argentine Crisis And Its Impact On Household Welfare", [online] Cepal.org. Available at: $<$ https://www.cepal.org/en/publications/10935-argen tine-crisis-and-its-impact-household-welfare> [Accessed 8 June 2020].

[8] Gajjar, N., (2013), "Factors Affecting Consumer Behavior", [online] Raijmronlineresearch.files.wordpress.com. Available at:

$<$ https://raijmronlineresearch.files.wordpress.com/2 017/08/2_10-15-dr-nilesh-b-gajjar.pdf> [Accessed 3 June 2020].

[9] IMF (2020), "The Great Lockdown: Worst Economic Downturn Since The Great Depression", [online] Available at: <https://blogs.imf.org/2020/04/14/the-great-lockdow n-worst-economic-downturn-since-the-great-depress ion/> [Accessed 28 June 2020].

[10]Hajikazemi, S., Ekambaram, A., Andersen, B. and Zidane, Y., (2016), "The Black Swan - Knowing the Unknown in Projects", Procedia - Social and Behavioral Sciences, 226, pp.184-192.

[11]Kelley, E. and Scheewe, L., (1975), "Buyer
Behavior in a Stagflation/Shortages Economy", Journal of Marketing, 39(2), p.44.

[12]Kuruppu, G. and De Zoysa, A., (2020), "COVID-19 and Panic Buying: An Examination of the Impact of Behavioural \& Biases", Electronic Journal.

[13]Pennings, J., Wansink, B. and Meulenberg, M., (2002), "A note on modeling consumer reactions to a crisis: The case of the mad cow disease", International Journal of Research in Marketing, 19(1), pp.91-100.

[14]Pennings, J. and Smidts, A., (2004), "Understanding And Managing Consumer Risk Behavior', [online] ResearchGate.net. Available at: $<$ https://www.researchgate.net/publication/2350558 8

[15] Robles, F. and Jerry, H., (2004), "Winning Strategies for the New Latin Markets", International Marketing Review, 21(6), pp.666-667.

[16] Ramya, N. and Mohamed Ali, S., (2020), "Factors Affecting Consumer Buying Behavior", [online] ResearchGate. Available at: <https://www.researchgate.net/publication/316429 866_Factors_affecting_consumer_buying_behavio r> [Accessed 30 May 2020]. 